\title{
Aplikasi Android pada Sistem Informasi Kalender Tanam Terpadu
}

\author{
Android Applications on Integrated Cropping Calendar Information \\ Systems
}

\author{
Fadhlullah Ramadhani, Haris Syahbuddin, dan Eleonora Runtunuwu \\ Balai Penelitian Agroklimat dan Hidrolog, Jl Tentara Pelajar la Bogor 16114 \\ Email:runtunuwu2001@yahoo.com
}

\begin{abstract}
Advance in information technology has grown very rapidly. It started with the use of mobile phones that are only used to send short messages or regular communication through smart phones. Indonesian Agency for Agricultural Research and Development, in their efforts of agricultural information dissemination, is trying to use the information technology as much as possible. One example is the deployment of integrated cropping calendar information, which is not only based on the web-site, but also based on SMS and Android. This paper aims to describe the development of application that can be used to disseminate information using the integrated katam Android based on mobile applications. The material used in the preparation of this application is certainly related to the planting calendar, namely the standing crop which is extracted from MODIS satellite imagery, CCTV monitoring records, the estimated time and acreage, the status of the vulnerability of flood and drought on district level, the status of plant pests, recommendation varieties and forecasting needs of seed, fertilizer recommendation and needs, and the mechanization of agriculture. The method used in general use Android-based systems development approach. The end result of this research is the availability and disuse Android applications in diverse cropping calendar information systems. In essence, the user can use a smartphone to get the latest information on agricultural crop calendars quickly. The rapid agricultural information is expected to help farmers and farming communities doing agricultural cultivation more accurately in order to avoid failure.
\end{abstract}

Keywords: Android, integrated cropping calendar, information systems.

\begin{abstract}
Abstrak
Kemajuan teknologi informasi dewasa ini sangat pesat. Mulai dengan penggunaan telepon selular yang hanya digunakan untuk mengirimkan pesan singkat atau berkomunikasi biasa sampai dengan telepon pintar (smart phone). Badan Penelitian dan Pengembangan Pertanian dalam usaha penyebaran informasi pertanian, berusaha menggunakan teknologi informasi tersebut semaksimal mungkin. Salah satu contoh adalah penyebaran informasi kalender tanam terpadu, yang bukan hanya berbasis website saja, tetapi juga berbasis SMS dan Android. Makalah ini bertujuan untuk memaparkan pengembangan aplikasi yang dapat digunakan untuk diseminasi informasi tanam terpadu menggunakan aplikasi mobile berbasis Android. Materi yang digunakan dalam penyusunan aplikasi ini tentunya terkait dengan kalender tanam, yaitu standing crop yang diekstrak dari citra satelit MODIS, data hasil monitoring CCTV, estimasi waktu dan luas tanam, status tingkat kerawanan banjir dan kekeringan tingkat kabupaten, status organisme pengganggu tanaman, rekomendasi varietas dan prakiraan kebutuhan benih, rekomendasi dan kebutuhan pupuk, dan mekanisasi pertanian. Metode yang digunakan secara umum adalah pendekatan pengembangan sistem berbasis Android. Hasil akhir dari penelitian ini adalah tersedianya dan terpakainya aplikasi Android pada sistem informasi katam terpadu. Pada intinya pengguna dapat menggunakan smartphone untuk mendapatkan informasi terkini mengenai kalender tanam pertanian secara cepat. Cepatnya mendapatkan informasi pertanian diharapkan membantu petani dan masyarakat pertanian melakukan budidaya pertanian secara lebih akurat agar terhindar dari kegagalan.
\end{abstract}

Kata kunci: Android, kalender tanam terpadu, sistem informasi.

Received: 5 Maret 2015; Revised: 7 April 2015; Accepted: 7 Mei 2015 ; Published online: 10 Juli 2015

(C)2015 INKOM 2015/15-NO414

\section{Pendahuluan}

Perkembangan penggunaan smart phone sangat pesat yang banyak diaplikasikan pada bidang pendidikan, kesehatan, pemerintahan dan perbankan. Peningkatan kepentingan dan aplikasi dari teknologi komunikasi dan informasi di 
bidang pertanian telah melahirkan e-pertanian [1]. Fokus utama e-pertanian adalah peningkatan pertanian melalui variasi teknologi dengan tujuan agar proses pertanian dan pengambilan keputusan lebih efisien.

Studi [2] menyajikan sebuah aplikasi untuk tablet Android yang berinteraksi dengan sistem kontrol maju berbasis Linux, Apache, MySQL, PHP, Perl atau Python (LAMP) untuk mengumpulkan dan memantau lahan perkebunan di Spanyol yang lebih efektif dan hemat uang.

Sedangkan studi [3] mengembangkan FarmManager yang merupakan aplikasi ponsel pintar Android dan terkait dengan basis data manajemen pertanian. Informasi yang dapat dicari petani adalah budidaya pertanian, peralatan, tenaga kerja, dan laporan budidaya Eropa, dan semuanya dapat dilakukan dengan sentuhan tombol layar ponsel pintar. Penggunaan perangkat lunak saat ini tersedia secara bebas dan ada lebih dari seribu petani menggunakannya di Yunani.

Sesma et.al. mengaplikasikan Android untuk menginstal sistem irigasi termasuk diameter pipa yang digunakan dalam instalasi irigasi [4]. Sistem otomatisasi dihubungkan dengan PC dalam bentuk software yang dikembangkan berdasar aplikasi mobile Android agar pengguna dapat dengan segera mengevaluasi respon seperti untuk melihat perubahan kebutuhan air seperti kultivation, dan kebutuhan air [5].

Mesas et. al. mengaplikasikan smart phone untuk bidang pertanian yang dikaitkan dengan pemerintahan [6]. Tujuannya adalah agar pengembangan dan implementasi dari aplikasi mobile untuk membuat pekerjaan lebih mudah. Alat yang digunakan adalah smartphone seperti GPS, kamera, Geofoto, dan komputer.

Teknologi elektronik canggih membuat ponsel cocok untuk estimasi jeruk hasil dengan teknik pengolahan citra [7]. Artikel ini mengusulkan sebuah metode baru untuk memperkirakan hasil jeruk dua minggu menjelang musim panen untuk pohon individual melalui pengolahan citra menggunakan ponsel Android (AMP). Prosedur ini pada dasarnya buah penghitungan software algoritma yang dikembangkan di Jawa yang menggunakan AMP panel sentuh monitor memperkirakan jeruk hasil. Foto Target diambil dalam kondisi alam oleh AMP. Pengolahan citra digunakan untuk memilih warna, segmen gambar, menghasilkan gambar binarisation, menghilangkan noise, dan memperkirakan jumlah buah. Kinerja perangkat lunak algoritma buahpenghitungan divalidasi dengan 40 sampel pohon jeruk dan metode mencapai presisi dan pengakuan rasio yang baik dari $90 \%$. Hasil penelitian menunjukkan bahwa pendekatan ini dapat digunakan untuk memperkirakan hasil buah dari pohon yang masing-masing yang merupakan informasi berharga untuk meramalkan hasil, jadwal panen rencana dan menghasilkan peta resep untuk praktek pengelolaan yang spesifik secara individu pohon dalam kebun itu. Dibantu oleh pendekatan yang diusulkan, seseorang dapat memperkirakan hasil jeruk tanpa peralatan mahal.

\section{Sistem informasi kalender tanam terpadu}

Badan Penelitian dan Pengembangan Pertanian (Balitbangtan) mengembangkan Sistem Informasi Kalender Tanam Terpadu (SI Katam Terpadu). Agar penyebaran informasi lebih cepat dan efisien ke seluruh Indonesia, maka informasi ini dikemas dalam bentuk perangkat lunak yang berbasis website [8,9]. Pengembangan sistem kalender tanam terpadu yang bersifat interaktif diharapkan dapat mempermudah pengambil kebijakan dalam merekomendasikan awal waktu tanam serta kebutuhan benih/varietas dan pupuk pada setiap awal musim tanam. SI Katam Terpadu Indonesia dapat diakses melalui alamat web litbang.deptan.go.id [10,11]. Balitbangtan memperbaharui informasi ini dua kali setahun pada setiap awal musim tanam musim kemarau untuk seluruh kecamatan di Indonesia yaitu bulan Maret dan September setiap tahunnya.

Detail informasi yang dihasilkan dari SI Katam Terpadu ini adalah:

\section{a. Standing crop}

Standing Crop menyediakan informasi luas tanam padi sawah per fase pertumbuhan (vegetatif 1, vegetatif 2, generatif 1, generatif 2) tiap kecamatan seluruh Indonesia berdasarkan citra MODIS. Overlay fase pertumbuhan tanaman dengan prediksi curah hujan dapat menggambarkan tingkat kekeringan agronomis. Dengan demikian kebutuhan pupuk, air, pestisida dan alsin per fase tumbuh dapat diketahui, sehingga dapat membantu perencanaan pertanian pada level kecamatan dengan cepat dan akurat.

\section{b. Monitoring CCTV}

Untuk meverifikasi dan mevalidasi SI Katam Terpadu, telah dilakukan pemasangan 55 monitoring online katam CCTV di 7 provinsi (Lampung, Banten, Jabar, Jateng, DIY, Jatim, dan Bali). Manfaat utama dari pengembangan program ini adalah sebagai salah satu verifikasi SI Katam Terpadu, seperti waktu dan pola tanam, dari gambar di depan jelas terlihat variasi kondisi penggunaan lahan sawah oleh petani. Manfaat kedua sebagai pemantauan terhadap kejadian 
bencana iklim di lahan pertanian, baik banjir, kekeringan, maupun serangan OPT. Sebagai contoh, banjir yang terjadi Januari 2014 di kecamatan Compreng, kabupaten Subang yang melanda lahan sawah kita. Curah hujan pada tanggal 16 dan 17 Januari yang kurang dari 20 $\mathrm{mm} /$ hari tidak menimbulkan banjir. Tetapi pada tanggal 18 Januari curah hujan sangat tinggi yaitu $150 \mathrm{~mm}$, wilayah sawah pertanian tergenang air selama dua hari yang berlanjut s.d. tanggal 19. Air mulai surut, pada tanggal 20 Januari ketika tidak ada hujan turun.

\section{c. Estimasi waktu dan luas tanam}

Estimasi waktu tanam untuk musim tanam ke depan merupakan informasi yang sangat dibutuhkan oleh petani. Badan Meteorologi Klimatologi dan Geofisika (BMKG) merupakan instansi resmi yang mengeluarkan estimasi prakiraan musim ke depan. Balitbang Pertanian menerjemahkan hasil prediksi tersebut ke waktu tanam tanaman bagi petani. Karena itu, penentuan estimasi waktu tanam merupakan keterkaitan antara data prediksi yang diperoleh dari BMKG dengan data kalender tanam yang dipublikasi oleh Badan Litbang Pertanian.

\section{d. Status tingkat kerawanan banjir dan kekeringan tingkat kebupaten}

Status tingkat kerawanan banjir dan kekeringan ditentukan dengan menggunakan indeks banjir (IDB), dan indeks kekeringan (IDK) per kabupaten. Apabila akumulatif IDB dan IDK selama setahun nilainya $>75 \%$ dikelompokkan sangat berat, 50-75\% dikelompokkan berat, 25$50 \%$ dikelompokkan sedang, dan $<25 \%$ dikelompokkan ringan. Ke depan, diharapkan sistem memuat rekomendasi teknologi untuk mengantisipasi kondisi banjir maupun kekeringan.

\section{e. Status Organisme Pengganggu Tanaman (OPT)}

Status wilayah setiap kabupaten yang terkena OPT dianalisis secara terpisah untuk 6 jenis OPT, yaitu wereng batang coklat, tikus sawah, penggerek batang padi, tungro, blast, dan kresek atau hawar daun bakteri (HDB). Dengan menggunakan indeks klasifikasi daerah serangan (KDS), hasil analisis status serangan OPT dikelompokan menjadi 4 pilihan, yaitu aman, sedang, rawan dan sangat rawan. f. Penentuan rekomendasi varietas dan prakiraan
kebutuhan benih

Varietas yang direkomendasikan didasarkan pada informasi tingkat kerentanan suatu kabupaten terhadap bencana dan juga potensi varietas yang mungkin dikembangkan. Pada perkembangannya, SI Katam Terpadu ini mampu memberikan rekomendasi varietas untuk tanaman jagung dan kedelai berdasarkan tingkat kerentanan kabupaten yang bersangkutan. Informasi varietas ini diperoleh dari Balai Besar Penelitian dan Pengembangan Padi (BB Padi) untuk padi, Balai Penelitian Tanaman Kacang-Kacangan dan Umbiumbian (Balitkabi) untuk kedelai dan Balai Penelitian Tanaman Serealia (Balitsereal).

\section{g. Rekomendasi dan kebutuhan pupuk}

Rekomendasi jenis pupuk setiap kecamatan pada intinya ditampilkan berdasarkan hasil estimasi komoditas apa yang ditanam, apakah padi, jagung dan atau kedelai. Keterkaitan dengan data lain adalah pada saat menampilkan data kebutuhan pupuk, merupakan hasil pengalian dosis per hektar dengan estimasi luas tanam musim ke depan.

\section{h.Mekanisasi pertanian}

Informasi mekanisasi pertanian terkait dengan kesiapan sarana pertanian, yaitu traktor dan thresher, baik kebutuhan, kekurangan dan usaha pemenuhan alat tersebut.

\section{Metodologi}

Pengembangan aplikasi ini terdiri dari langkahlangkah sebagai berikut:

\subsection{Desain antarmuka aplikasi berbasis Android}

Aplikasi yang akan dibangun akan berbasis internet, sehingga data dan informasi yang diinginkan oleh pengguna akan mendapatkan yang terbaru tanpa harus memperbarui aplikasi yang ada. Informasi yang akan dimunculkan sesuai dengan format sms yang telah dibuat untuk mempermudah pembangunan aplikasi ini karena pembuatan aplikasi ini merupakan yang pertama dilakukan Badan Litbang Pertanian. Tampilan harus memuat logo kementerian pertanian dan logo inovasi pertanian. Selain itu juga, aplikasi harus mempunyai fitur tambahan seperti menyalin hasil informasi ke aplikasi lain menggunakan fasilitas copy-paste. Pengguna menggunakan textbox untuk mengisi administrasinya bukan listbox untuk mempermudah pemakaian karena terdapat 1 nasional, 33 provinsi, 497 kabupaten, dan 6769 kecamatan yang dapat diambil informasi kalender tanam terpadu. 


\subsection{Pembuatan aplikasi berbasis Android menggunakan Eclipse}

Untuk mempermudah pembuatan aplikasi ini, maka digunakanlah Eclipse (Gambar 1), sebuah perangkat lunak Integrated Development Enviroment (IDE) yang open-source berbasis Java. Untuk aplikasi ini dirancang untuk dapat berjalan untuk Android versi 2.3.6 sampai dengan 4.2.1. Adapun file yang dibutuhkan adalah activity_katam_terpadu.xml untuk mengatur antarmuka pengguna, KatamTerpadu.java untuk mengatur algoritma aplikasi, strings.xml untuk menyimpan parameter, katam_terpadu.xml untuk mengatur menu di aplikasi, dan AndroidManifest.xml untuk menyimpan pengaturan aplikasi.

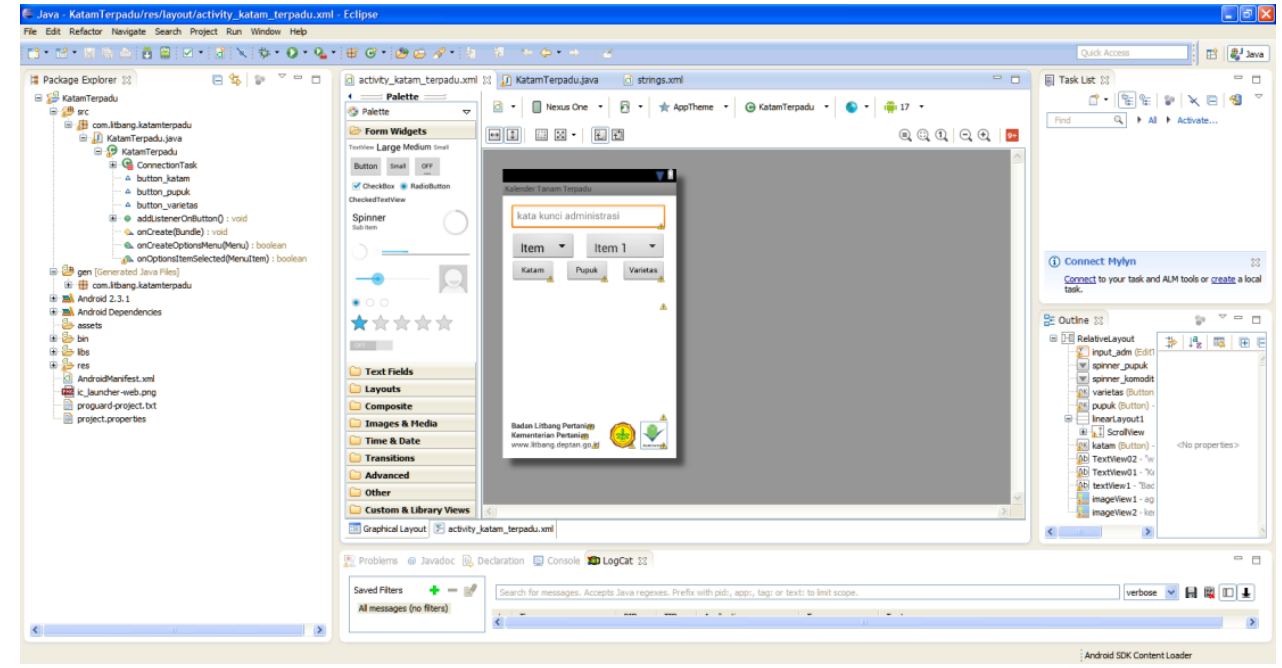

Gambar 1. Tampilan aplikasi Eclipse untuk membuat aplikasi berbasis Android

\subsection{Uji coba aplikasi menggunakan simulator dari Android Development Tools (ADT) dan perbaikan.}

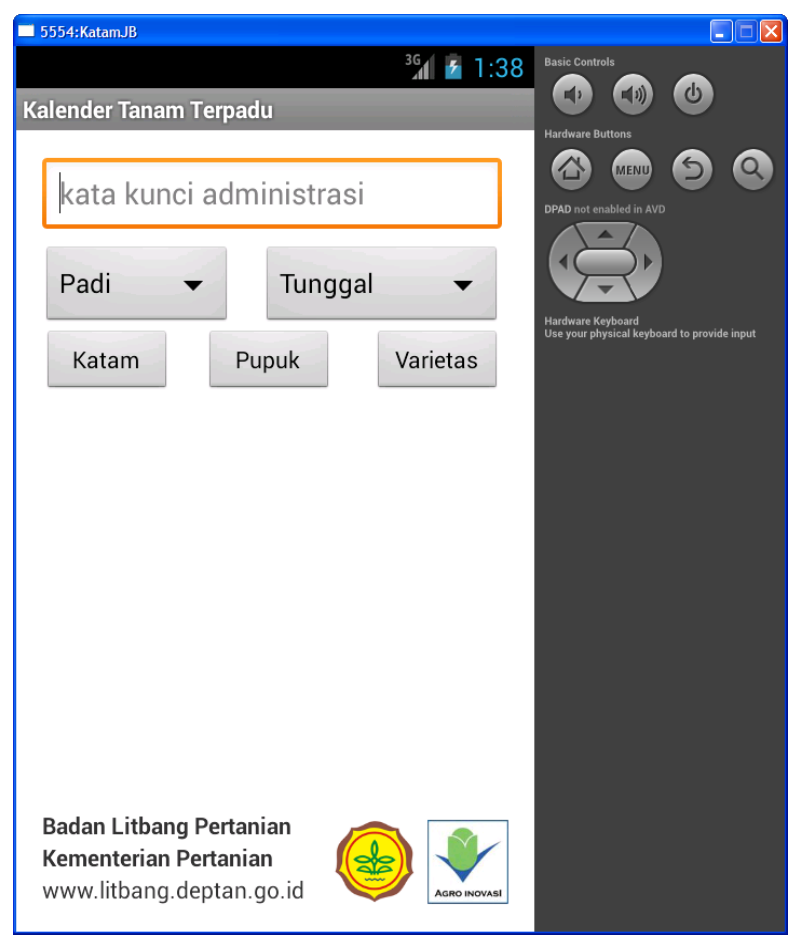

Gambar 2. Tampilan simulator ADT Android versi 4.2.2
Aplikasi berbasis Android yang hanya jalan di telepon pintar dapat dijalankan menggunakan simulator yang terhubung dengan Eclipse. Adapun versi yang dipakai adalah Android 2.3.6 dan Android 4.2.2 (Gambar 2).

\subsection{Upload aplikasi ke Google Play Store}

Untuk pengguna mendapatkan aplikasi ini, Google menyediakan Google Play Store for Developer (Gambar 3), sehingga pengembang dapat mengunggah aplikasi yang telah dibuat untuk disimpan di took aplikasi ini. Aplikasi yang telah dibuat bersifat gratis dan bebas iklan sehingga siapa saja dapat mengunduh aplikasi ini tanpa harus membeli atau mendapatkan iklan yang bisa dapat mengganggu.

\section{Hasil dan pembahasan}

Judul dari aplikasi ini adalah "Katam Terpadu Versi Ringan" (Gambar 4 dan Gambar 5), versi ringan berarti data dan informasi yang didapatkan harus terhubungan dengan internet dan server katam terpadu. Cara ini sangat efisien dan efektif tapi membutuhkan koneksi internet secara otomatis. Adapun fitur yang ada adalah sebagai berikut: 


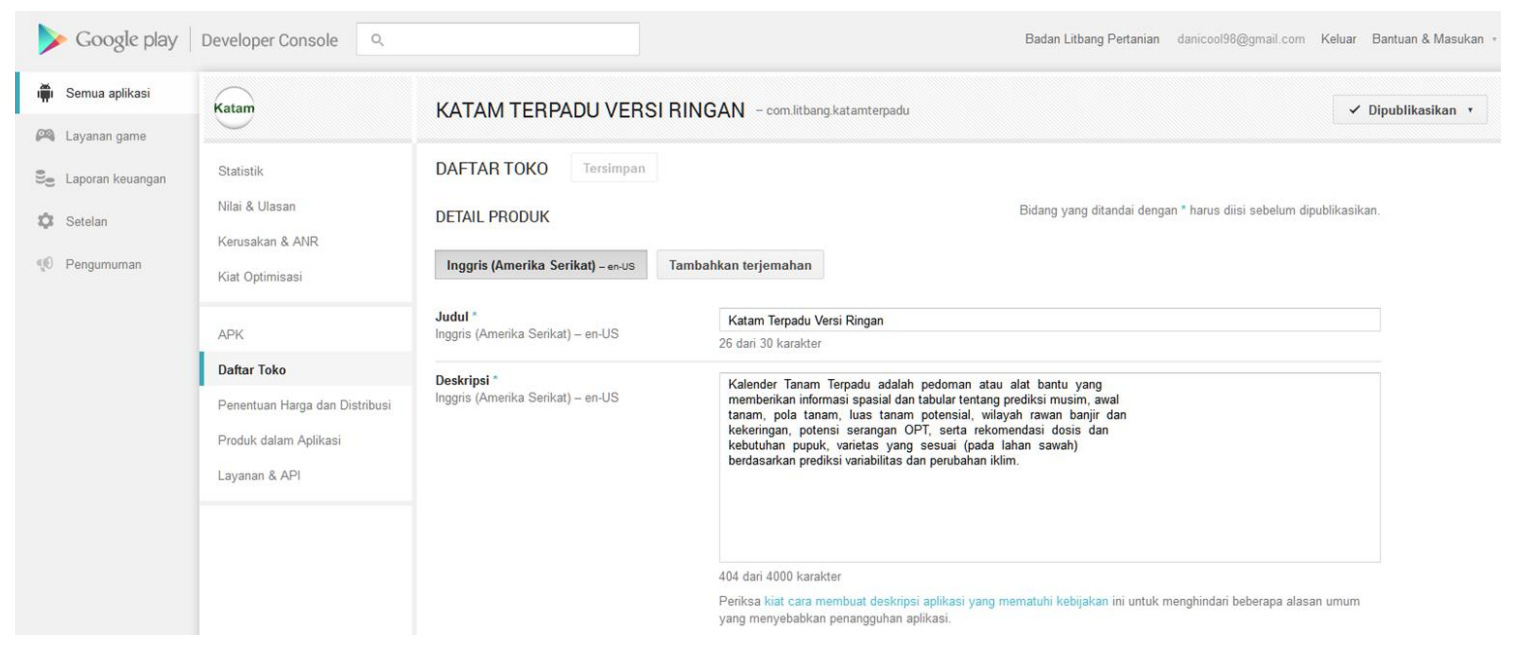

Gambar 3. Tampilan Google Play Developer

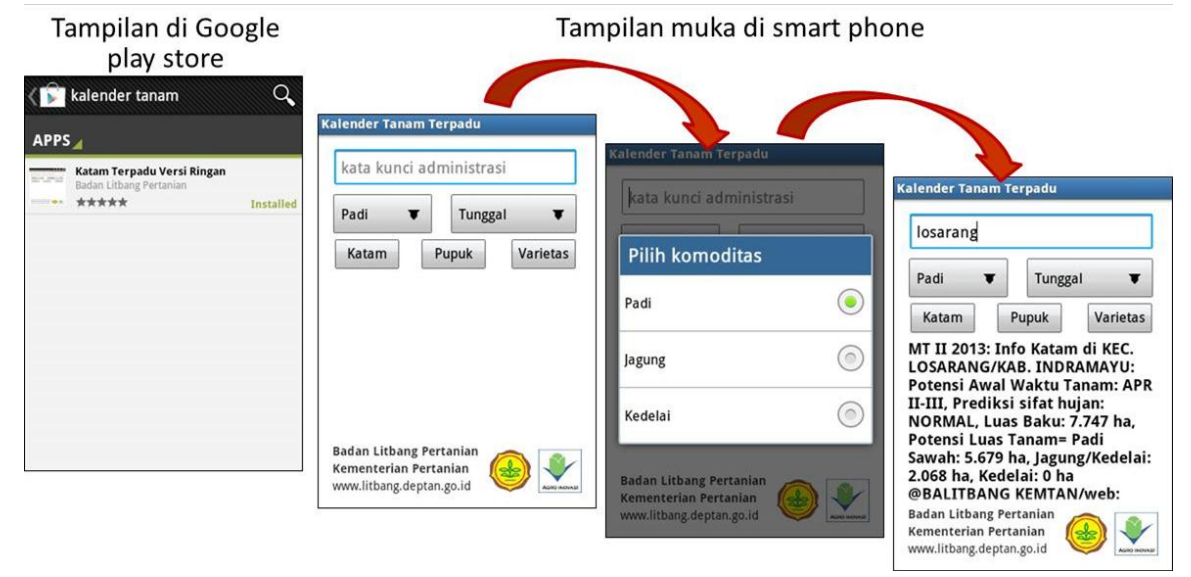

Gambar 4. Tampilan penggunaan aplikasi katam versi ringan di sistem operasi Android versi 4
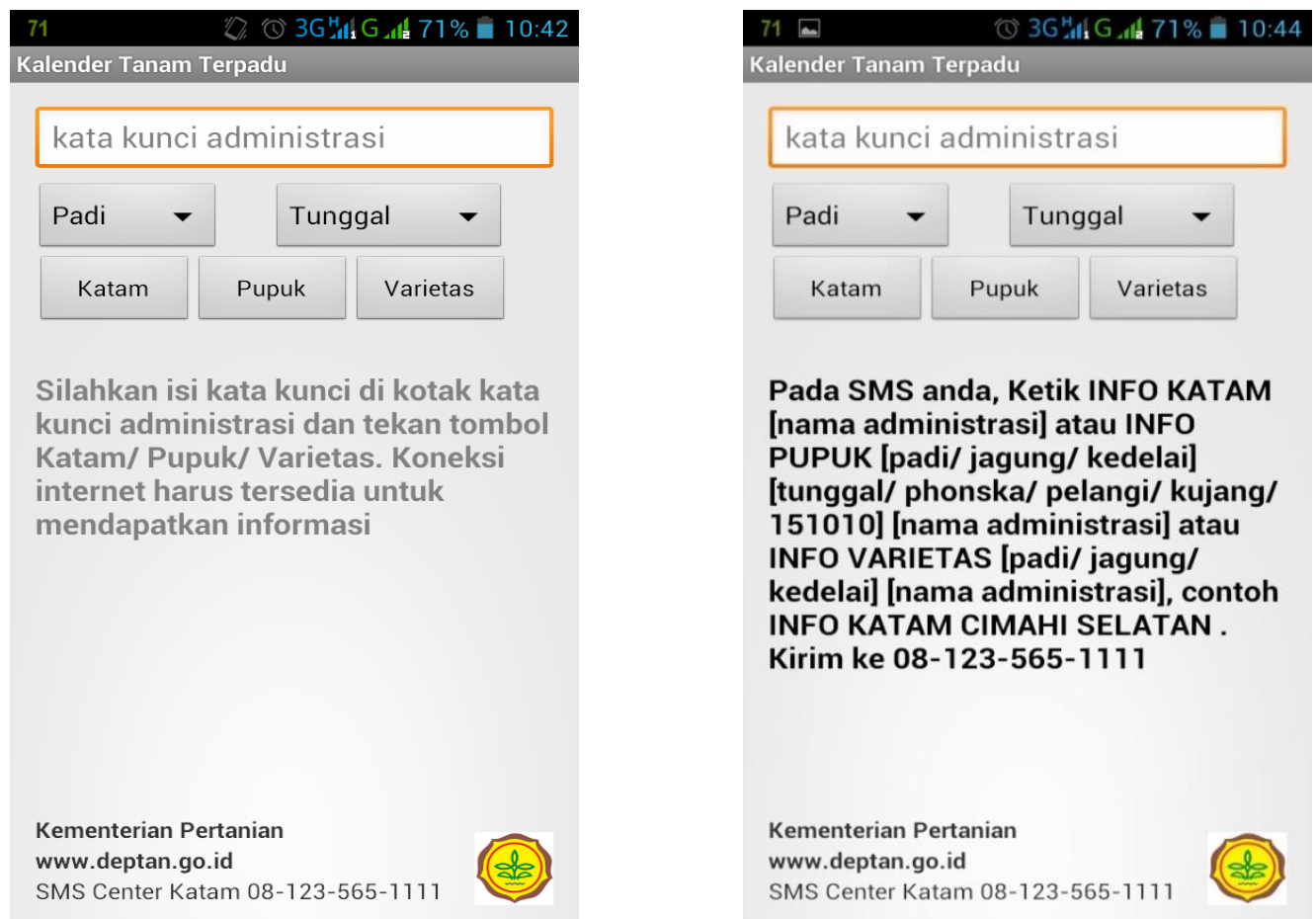

Gambar 5. Tampilan aplikasi katam terpadu untuk Android versi 5 
a. Dapat mencari secara "pintar" kata kunci administrasi mulai dari tingkat nasional sampai dengan kecamatan.

b. Dapat mencari informasi kalender tanam, pupuk, varietas.

c. Hasil informasi yang didapatkan dapat dikopi dan dimasukkan ke aplikasi lain yang diinginkan seperti Memo, Messaging, dan lainlain.

Aplikasi ini menggunakan Google Play sebagai tempat penyimpanan aplikasi secara resmi untuk sistem operasi Android, sehingga pengguna harus menginstal dari aplikasi Google Play untuk dapat digunakan di perangkat pengguna.

\section{Kesimpulan}

Sistem aplikasi katam terpadu yang telah berkembang pesat dari dua subsistem (aplikasi web dan desktop) menjadi sistem yang lebih komprehensif menjadi tujuh subsistem, yang terdiri dari aplikasi web katam terpadu, aplikasi desktop katam terpadu, aplikasi SMS center, aplikasi Android versi ringan, aplikasi entri data melalui Google Drive, aplikasi desktop pemantauan katam, dan aplikasi web pemantauan katam.

Kemudahan pengguna untuk mengakses data katam terpadu dari tingkat pusat sampai dengan petani melalui beberapa jalur komunikasi diharapkan dapat menurunkan kegagalan petani akibat perubahan iklim.

\section{Daftar pustaka}

[1] M. Arroqui, C. Mateos, C. Machado, A. Zunino. "RESTful Web Services improve the efficiency of data transfer of a whole-farm simulator accessed by Android smartphones". Computers and Electronics in Agriculture, vol. 87, Pages 14-18, September 2012.

[2] F.G. Montoya, J. Gómez, A. Cama, A. ZapataSierra, F. Martínez, J. Luis De La Cruz, and F. Manzano-Agugliaro. "A Monitoring System for Intensive Agriculture Based on Mesh Networks and the Android System", Computers and Electronics in Agriculture, vol. 99, Pages 14-20, November 2013.

[3] Th. Lantzos, G. Koykoyris, and M. Salampasis. "FarmManager: An Android Application for the Management of Small Farms". Procedia Technology, vol. 8, Pages 587-592, 2013.

[4] J. Sesma, J.M. Molina-Martínez, F. CavasMartínez, D.G. Fernández- Pacheco. "A mobile application to calculate optimum drip irrigation lateral". Agricultural Water Management, vol. 151, Pages 13-18, 31 March 2015.

[5] B. Delgado, M. Paredes, M. Martínez. "Software application for calculating solar radiation and equivalent evaporation in mobile devices". Agricultural Water Management, vol. 151, Pages 30-36, 31 March 2015.

[6] F. J. Mesas-Carrascosa, I. L. Castillejo-González, M. Sánchez de la Orden, A. Ferrer. "Real-time mobile phone application to support land policy". Computers and Electronics in Agriculture, vol. 85, Pages 109-111, July 2012.

[7] A. Gong, J. Yu, Y. He, and Z. Qiu. "Citrus Yield Estimation Based on Images Processed by an Android Mobile Phone". Biosystems Engineering, vol. 115, Issue 2, Pages 162-170, June 2013.

[8] Ramadhani F., E. Runtunuwu, H. Syahbuddin. "Pengembangan Sistem Teknologi Informasi Kalender Tanam Terpadu Berbasis Web". Jurnal Informatika Pertanian, vol. 22, no 2, pages 103112, 2012.

[9] Runtunuwu E., H. Syahbuddin, F. Ramadhani. "Kalender tanam sebagai instrumen adaptasi perubahan iklim”. Dalam Kajian strategi kebijakan sektor pertanian menghadapi perubahan iklim. Badan Penelitian dan Pengembangan Pertanian. Badan Penelitian dan Pengembangan Pertanian. Jakarta, pages 271-297. 2013a

[10] Runtunuwu E., H. Syahbuddin, F. Ramadhani, A. Pramudia, D. Setyorini, K. Sari, Y. Apriyana, E. Susanti, Haryono. "Inovasi Kelembagaan Sistem Informasi Kalender Tanam Terpadu Mendukung Adaptasi Perubahan Iklim untuk Ketahanan Pangan Nasional". Jurnal Pengembangan Inovasi Pertanian, vol. 6, no. 1, pages 44-52, 2013 b.

[11] Runtunuwu E., H. Syahbuddin, F. Ramadhani, A. Pramudia, D. Setyorini, K. Sari, Y. Apriyana, E. Susanti, Haryono, P. Setyanto., I. Las, M. Sarwani. "Sistem Informasi Kalender Tanam Terpadu: Status Terkini dan Tantangan ke depan". Jurnal Sumber Daya Lahan, vol. 6, no. 2, pages 67-78, 2012. 